\title{
KLINIČKE KARAKTERISTIKE PACIJENATA SA OPSTRUKTIVNOM APNEJOM U SPAVANJU
}

\author{
CLINICAL CHARACTERISTICS OF OBSTRUCTIVE SLEEP APNEA PATIENTS
}

\author{
Sanja Glišić, Krsto Jandrić, Jelena Bogdanić, Igor Dumanović, Jelena Pijetlović, Mladen \\ Bursać, Spomenka Paurević-Čutura, Draženko Vuković, Jasminka Aličehajić, Zorana Čović, \\ Nataša Vajić, Ognjen Marinković
}

\begin{abstract}
Sažetak: Opstruktivna apneja u spavanju je često oboljenje koje se u oko 85\% pacijenata ne dijagnostikuje. Karakteriše se ponavljanim prekidima disanja u spavanju koji su uzrokovani potpunim ili djelimičnim kolapsom gornjih disajnih puteva, što izaziva pad saturacije kiseonika u krvi i posljedično isprekidan, neokrepljujući san.

U našem istraživanju smo ispitali kliničke karakteristike 33 pacijenta koji su uradili polisomnografski pregled u Specijalnoj bolnici za kardiovaskularnu rehabilitaciju „Hercegovina“ u ZTC Banja Vrućica u periodu od 01.01.2017. do 31.12.2017. godine.

Cilj našeg istraživanja je utvrditi učestalost riziko faktora za opstruktivnu apneju u spavanju kod naših ispitanika i utvrditi učestalost $i$ vrstu komorbiditeta.

U našoj grupi ispitanika postojala je blaga predominacija muškog pola (57,5\% ispitanika), prosječna starost 61 godina (SD 13,03). Najveći broj oboljelih (70\%) je u starosnoj grupi 60 i više godina. BMI veći od 30 je imalo $70 \%$ ispitanika. Obim vrata veći od $40 \mathrm{~cm}$ je imalo $70 \%$ ispitanika. U grupi ispitanika sa visokim rizikom za apneju u spavanju (STOP BANG 5-8 bodova) je bilo 88,8\% ispitanika. Jedan ili više komorbiditeta je imalo 75\% ispitanika, od čega je najčešća bila hipertenzija, bolest koronarnih krvnih sudova, HOBP, šećerna bolest $i$ različite aritmije.
\end{abstract}

Ključne riječi: apneja u spavanju, riziko faktori, komorbiditeti

\section{UVOD}

Sindrom opstruktivne apneje u spavanju (OSAS) je često oboljenje koje se javlja kod 3-7\% odraslih muškaraca, i kod 2 do $5 \%$ odraslih žena (1). Ovo oboljenje se u oko $70-80 \%$ pacijenata ne dijagnostikuje $(2,3)$. Karakteriše se ponavljanim prekidima disanja u spavanju koji su uzrokovani potpunim (apneja) ili djelimičnim (hipopneja) kolapsom gornjih disajnih puteva, što izaziva pad saturacije kiseonika u krvi i posljedično isprekidan, neokrepljujući san.

Opstruktivna apneja u spavanju se dijagnostikuje ukoliko je apneja-hipopneja (AHI) indeks veći od 5. Apneja-hipopneja indeks predstavlja broj apneja i hipopneja po satu spavanja. Sindrom opstruktivne apneje u spavanju (OSAS) se definiše kao AHI $>5$ uz prisustvo simptoma $\mathrm{u}$ vidu pospanosti i dnevnog umora.

OSAS se češće javlja kod muškaraca. Prema rezultatima različitih studija odnos muškaraca i žena sa
OSAS je 2 do $3: 1(4,5,6,7)$. Ova razlika se gubi poslije 50-te godine starosti (8). Pretpostavlja se da je ova polna distribucija uzrokovana anatomskim razlikama gornjih disajnih puteva i uticajem hormona $(9,10,5)$. Smatra se da ovu razliku uzrokuje i ,nesenzitivnost" muških partnera u krevetu koji rjeđe čuju i rjeđe prepoznaju da im partnerka ima problem prilikom spavanja (1).

Iako se OSAS javlja u svim starosnim dobima, od djetinjstva do duboke starosti, češće se javlja kod starijih osoba $(11,5)$.

Povećana tjelesna masa je značajan riziko faktor za apneju u spavanju, $70 \%$ pacijenata sa OSA su gojazni $(4,5,6,11,12)$.

Pacijenti sa OSA veoma često imaju komorbiditete (13-16). Pacijenti sa hroničnom srčanom insuficijencijom imaju opstruktivnu ili centralnu apneju u spavanju u preko $50 \%$ slučajeva. Pacijenti sa ishemijskom bolesti srca imaju OSA u do 50\% slučajeva. Pacijenti sa šećernom bolesti imaju OSA u $50-80 \%$ slučajeva. 


\section{MATERIJAL I METODE}

U našem istraživanju smo ispitali kliničke karakteristike 33 pacijenta koji su uradili polisomnografski pregled u Specijalnoj bolnici za kardiovaskularnu rehabilitaciju „Hercegovina“ u ZTC Banja Vrućica u periodu od 01.01.2017. do 31.12.2017. godine.

Svi pacijenti koji su se $\mathrm{u}$ navedenom periodu samoinicijativno javili na pregled ili su upućeni na pregled na osnovu preporuke ordinarijusa su uključeni $\mathrm{u}$ ispitivanje.

Nakon uzimanja anamnestičkih podataka i fizikalnog pregleda, 27 pacijenata je ispunilo STOP BANG upitnik. STOP-BANG je standardizovani upitnik za procjenu rizika od postojanja sindroma opstruktivne apneje u spavanju (OSA). Upitnik je inicijalno kreiran radi preoperativne procjene prisustva OSA kod hirurških pacijenata, ali je kasnije uspješno validiran i u drugim populacijama. Upitnik se sastoji iz dva dijela. Subjektivni deo (STOP) upitnika služi za samoprocjenu rizika od OSA i sadrži 4 pitanja na koje ispitanik odgovara sa Da ili Ne. Pitanja se odnose na glasno hrkanje, dnevni umor/pospanost, uočene prekide u disanju tokom spavanja kao i na prisustvo povišenog krvnog pritiska. Svaki pozitivni odgovor se boduje sa jednim poenom. Visok rizik od OSA postoji ukoliko su dva ili više odgovora pozitivni. Objektivni deo (BANG) upitnika se sastoji od četiri $\mathrm{Da} / \mathrm{Ne}$ pitanja na koje odgovor daje član medicinskog tima koji je pregledao ispitanika. Pitanja se odnose na indeks tjelesne mase (da li je BMI $\geq 35 \mathrm{~kg} / \mathrm{m} 2$ ), godine života (da li je ispitanik stariji od 50 godina), obim vrata (da li je $\mathrm{OV} \geq 40 \mathrm{~cm}$ ) i pol ispitanika (da li je muškog pola). Skorovanje STOP-BANG upitnika se radi na osnovu modela predloženog od strane autora. Ukupni skor upitnika predstavlja sumu poena dobijenih na osnovu broja pozitivnih odgovora i može biti $u$ rasponu od 0-8 poena. Kao granična vrijednost prisustva visokog rizika se koristi skor 3, a u novijim istraživanjima autora upitnika preporučuje se i skor 5 . $\mathrm{U}$ ovom istraživanju rezultati su prikazani kategorijalno (STOP-BANG $\geq 3$ ukazuje na prisustvo umjerenog, a STOP-BANG $\geq 5$ ukazuje na prisustvo visokog rizika od OSA).

U cilju postavljanja dijagnoze apneje u spavanju urađena je cjelonoćna respiratorna poligrafija koristeći aparate Alice Night One, Phillips i Alice PDx, Phillips. Procedura je izvršena primjenom standardnih tehnika u skladu sa međunarodno priznatim normama. Respiratona poligrafija obuhvata simultano kontinuirano cjelonoćno praćenje protoka vazduha pri disanju (putem transduktora nazalnog pritiska vazduha), pokreta grudnog koša i abdomena pri disanju (indukciona pletizmografija), oksimetrije $\mathrm{i}$ položaja tijela. Polisomnografski zapisi su manuelno skorovani $\mathrm{u}$ skladu sa standardnim međunarodno prihvaćenim protokolom navedenim u Priručniku za ocenjivanje sna i događaja vezanih za spavanje Američke akademije za medicinu sna. PSG zapisi su analizirani u dijagnostičkom programu Sleepware G3 (Philips Respironics). Korišćena je definicija apneje i hipopneje navedena u smernicama AASM iz 2007. godine. Apneja (kompletni prekid u disanju) je registrovana ukoliko bi došlo do pada maksimalne ekskurzije signala protoka vazduha za $90 \%$ ili više u odnosu na osnovnu aktivnost, u trajanju od najmanje 10 sekundi. Hipopneja (parcijalni prekid disanja) je prepoznata ukoliko bi postojao pad ekskurzije signala detektora pritiska vazduha za $\geq 50 \%$ u odnosu na osnovni nivo, praćen padom saturacije kiseonikom od najmanje 3\%. Apneja-hipopneja indeks (AHI) je korišćen za postavljanje dijagnoze apneje u spavanju kao i za određivanje težine bolesti. Smatra se da je apneja u spavanju blagog stepena ukoliko je $\mathrm{AHI} \geq 5 \mathrm{i}$ $<15$ po satu spavanja, umjerenog do teškog stepena ukoliko je $A H I \geq 15$ i $<30$, i veoma teškog stepena ukoliko je $\mathrm{AHI} \geq 30$ po satu spavanja.

Rezultati su statistički obrađeni i predstavljeni parametrima deskriptivne statistike.

\section{CILJ RADA}

Cilj našeg istraživanja je utvrditi učestalost riziko faktora za opstruktivnu apneju u spavanju kod naših ispitanika i utvrditi učestalost i vrstu komorbiditeta.

\section{REZULTATI}

U našoj grupi ispitanika postojala je blaga predominacija muškog pola $(57,5 \%$ ispitanika), prosječna starost 61 godina (SD 13,03). 
Slika 1. Prikaz polne strukture ispitanika

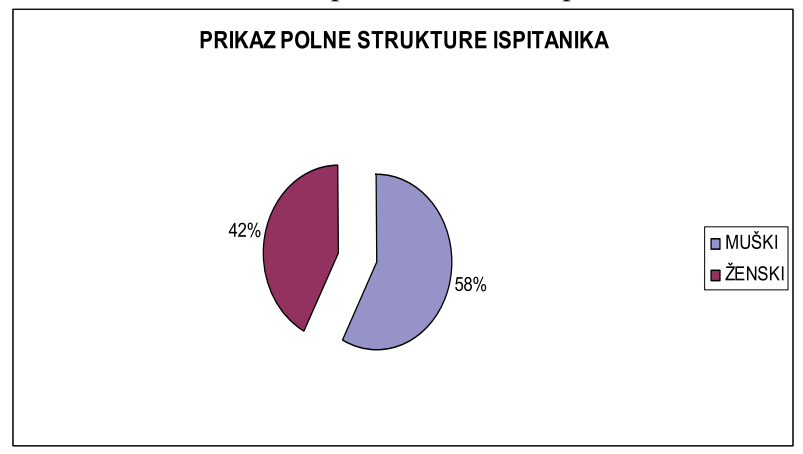

Najveći broj oboljelih (70\%) je u starosnoj grupi 60 i više godina.

\section{Slika 2. Prikaz starosne strukture ispitanika}

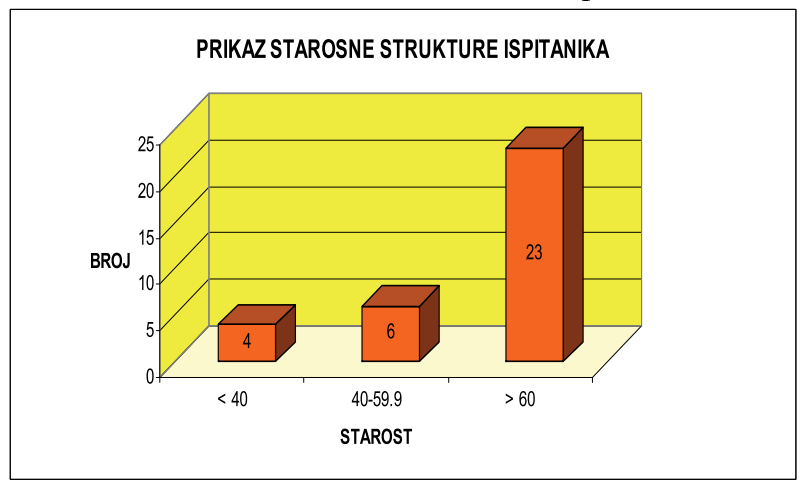

BMI veći od 30 je imalo $70 \%$ ispitanika.

Slika 3. Prikaz ispitanika prema vrijednostima BMI

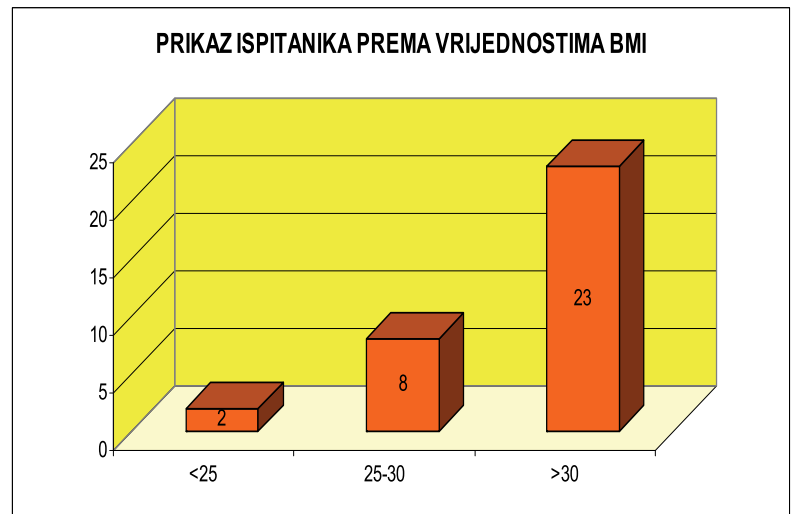

Obim vrata veći od $40 \mathrm{~cm}$ je imalo $70 \%$ ispitanika.
Slika 4.

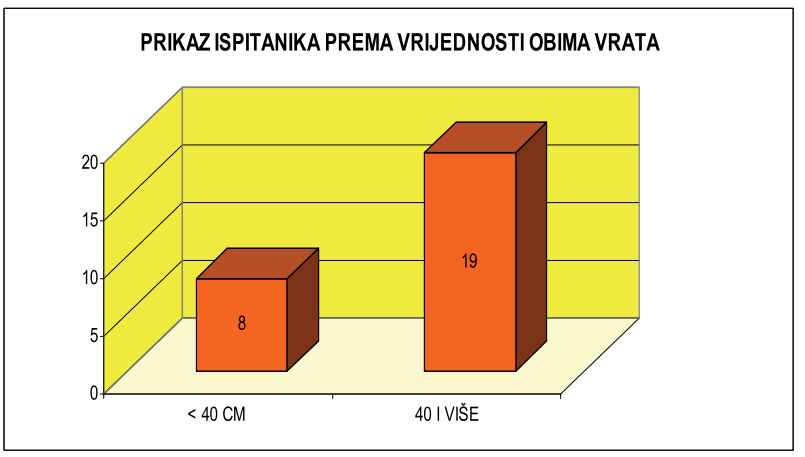

U grupi ispitanika sa visokim rizikom za apneju $\mathrm{u}$ spavanju (STOP BANG 5-8 bodova) je bilo 88,8\% ispitanika.

Slika 5. Prikaz ispitanika prema vrijednostima STOP BANG upitnika

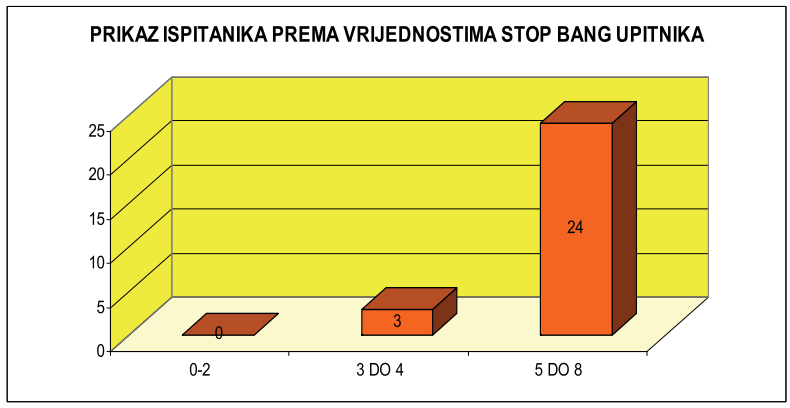

Najčešće smo dijagnostikovali tešku osptruktivnu apneju u spavanju ( OSA).

Slika 6. Prikaz ispitanika prema težini OSA

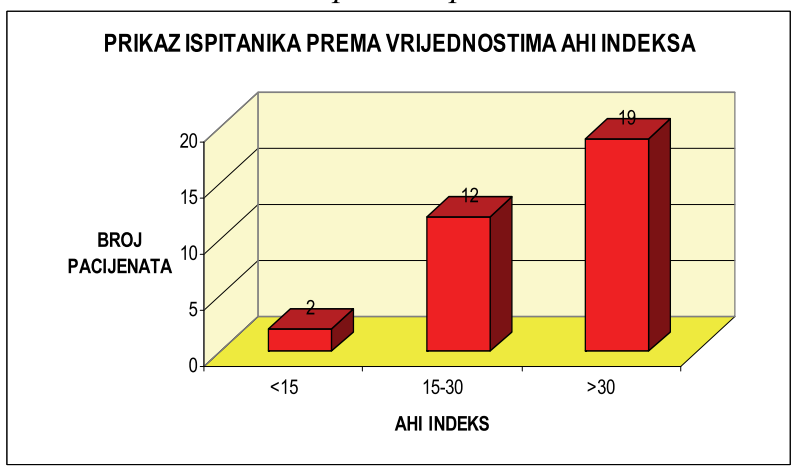

Jedan ili više komorbiditeta je imalo $75 \%$ ispitanika, od čega je najčešća bila hipertenzija, bolest koronarnih krvnih sudova, HOBP, šećerna bolest $\mathrm{i}$ različite aritmije. 
Slika 6. Prisustvo komorbiditeta kod ispitanika

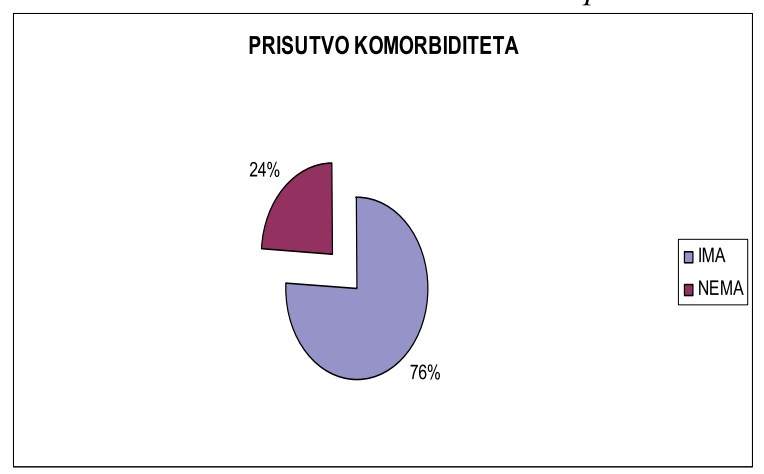

Slika 7. Učestalost različitih komorbiditeta kod pacijenata sa OSA

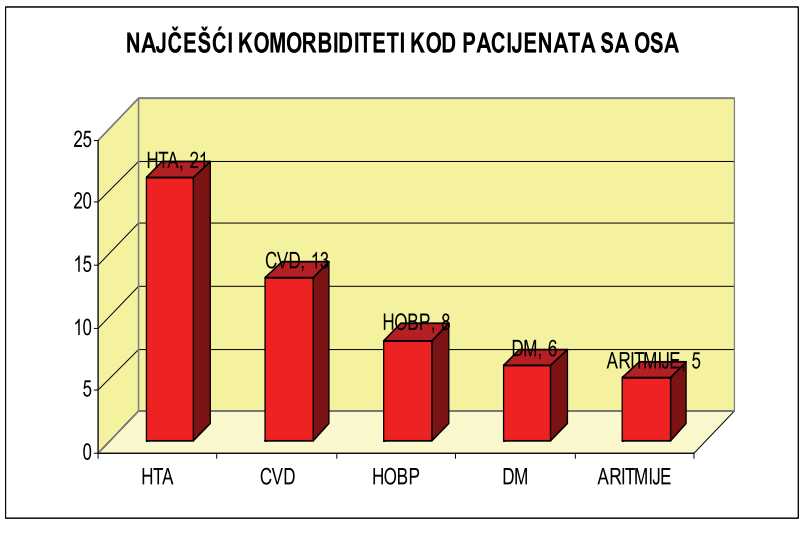

\section{DISKUSIJA}

U našem istraživanju smo sindrom opstruktivne apneje u spavanju (OSAS) dijagnostikovali u skoro istom omjeru i kod muškaraca i kod žena $(58 \%$ muškaraca i $42 \%$ žena). Drugi autori su dokazali da je muški pol faktor rizika za razvoj OSAS i OSAS je kod muškaraca dijgnostikovan 2 do 3 puta češće $(4-7,9)$. Međutim, ova razlika se gubi poslije pedesete godine života, odnosno kod žena u menopauzi je prevalenca ovog oboljenja ista kao i kod muškaraca (8). U našem uzorku su sve osobe ženskog pola (osim jedne žene) bile starije od 50 godina, odnosno u menopauzi, što objašnjava ovakvu polnu distribuciju.

Posmatrajući starosnu strukturu naših ispitanika uočava se da je najveći broj oboljelih u grupi starijih od 60 godina. Ovaj podatak se slaže sa podacima iz većine studija koje su pokazale da se prevalenca ovog oboljenja progresivno povećava sa starošću ispitanika $(5,11,17)$ tako da su našli da je prevalenca $3,2 \%$ u grupi ispitanika starih od $20-44$ godine, $11,3 \%$ u grupi 45-64 godine i $18,1 \%$ u grupi starijih od 65 godina (11).
U našem ispitivanju 70\% ispitanika je bilo gojazno. I druge studije potvrđuju da je gojaznost veoma česta kod pacijenata sa OSAS i da je prisutna u više od $60 \%$ pacijenata koji se ispituju zbog sumnje na OSAS (33). Gojaznost je najsnažniji prepoznati faktor rizika za OSAS u epidemiološkim studijama širom svijeta $(4,5,6,11,12)$. U Wisconsin Sleep Cohort Study je uočeno da povećanje tjelesne težine za $10 \%$ dovodi do povećanja apneja-hipopneja indeksa (AHI) za $32 \%$ i do povećanja rizika za razvoj srednje teške do teške OSA za 6 puta.

U našem ispitivanju $88,8 \%$ ispitanika, koji su ispunili STOP-BANG upitnik, je imalo skor veći od 5 bodova i kod njih smo u 77,7\% slučajeva dijagnostikovali srednje tešku i tešku OSAS. STOPBang upitnik je validiran upitnik za procjenu rizika od postojanja sindroma opstruktivne apneje u spavanju (OSAS). Senzitivnost upitnika da detektuje bilo koju opstruktivnu apneju u spavanju (OSA) ( AHI $>5$ ) je $90 \%$, srednje tešku OSA (AHI $\geq 15)$ je $94 \%$ i tešku OSA ( AHI $\geq 30$ ) je 96\% (18). Sa povećanjem STOPBang skora povećava se vjerovatnoća srednje teške i teške OSA. Kod STOP-Bang skora od 7 i 8 bodova vjerovatnoća teške OSA je bila $75 \%$ u grupi ispitanika liječenih u klinikama za poremećaje spavanja (18) što se slaže i sa našim rezultatima.

U našoj studiji jedan ili više komorbiditeta je imalo $75 \%$ ispitanika a najčešći su bili hipertenzija (64\%), koronarna bolest srca (39\%) i HOBP (24\%). Učestalost hipertenzije kod pacijenata sa OSAS se procjenjuje između 30 i $70 \%$ (34), što se slaže i sa našom studijom. U našem ispitivanju smo kod 39\% ispitanika imali pozitivne anamnestičke podatke za koronarnu bolest srca ( preležan infarkt miokarda ili stanje nakon revaskularizacija miokarda). Ovi podaci odgovaraju podacima nađenim u literaturi gdje je koronarna bolest srca bila prisutna u $33,2 \%$ pacijenata (35).

Učestalost hronične opstruktivne bolesti pluća (HOBP) u našoj grupi ispitanika je bila $24 \%$ što se slaže sa podacima nađenim u literaturi prema kojima se učestalost HOBP kod pacijenata koji imaju OSAS kreće od 11-29\% $(31,32)$.

\section{ZAKLJUČAK}

Naša studija je potvrdila da su starost i gojaznost u visokom procentu udruženi sa opstruktivnom apnejom u spavanju. Visok skor STOP-Bang upitnika je bio udružen sa težim oblicima OSAS (srednje teška i 
teška). Komorbiditeti su česti kod pacijenata sa OSAS, a najčešće se javljaju hipertenzija, koronarna bolest srca i HOBP

\section{LITERATURA}

1. Punjabi NM. The Epidemiology of Adult Obstructive Sleep Apnea. Proc Am Thorac Soc 2008;5:136-143.

2. Young T, Evans L, Finn L, Palta M. Estimation of the clinically diagnosed proportion of sleep apnea syndrom in middle-aged men and women. Sleep 1997;20:705706.

3. Kapur V, Strohl KP, Redline S, Iber C, O'Connor G, Nieto J. Underdiagnosis of sleep apnea syndrome in US communities. Sleep Breath 2002;6:49-54.

4. Young T, Palta M, Dempsey J, Skatrud J, Weber S, Badr S. The occurence of sleep-disorded breathing among middle-aged adults. $\mathrm{N}$ Engl $\mathrm{J}$ Med 1993;328:1230-1235.

5. Bixler EO, Vgontzas AN, Lin HM, Ten Have T, Rein $\mathrm{J}$, Vela-Bueno A, Kales A. Prevalence of sleepdisorded breathing in women: effects of gender. Am J Respir Crit Care Med 2001;163:608-613.

6. Duran J, Esnaola S, Rubio R, Iztueta A. Obstructive sleep apnea-hypopnea and related clinical features in a population-based sample of subjects aged 30-70 yr. Am J Respir Crit Care Med 2001:163:685-689.

7. Redline S, Kump K, Tishler PV, Browner I, Ferrete V. Gender differences in sleep disorded breathing in a community-based sample. Am J Respir Crit Care Med 1994;149:722-726.

8. Tishler PV, Larjin EK, Schluchter MD, Redline S. Incidence of sleep-disorded breathing in an urban adult population: the relative importance of risk factors in the development of sleep-disorded breathing. JAMA 2003;289:2230-2237.

9. Jordan AS, McEvoy RD. Gender differences in sleep apnea: epidemiology, clinical presentation and pathogenic mechanisms. Sleep Med Rev 2003;7:377389.

10. Jordan AS, McEvoy RD, Edwards JK, Schory K, Yang $\mathrm{CK}$, Catcheside PG et al. The influence of gender and upper airway resistance on the ventilatory response to arousal in obstructive sleep apnoea in humans. J Physiol 2004;558:993-1004.

11. Bixler EO, Vgontzas AN, Ten Have T, Tyson K, Kales A. Effects of age on sleep apnea in men: I. Prevalence and severity. Am J Respir Crit Care Med 1998;157:144-148.

12. Peppard PE, Young T, Palta M, Dempsey J, Skatrud J. Longitudinal study of moderate weight change and sleep-disorded breathing. JAMA 2000;284:3015-3021.
13. Peppard PE, Young T, Palta M, Skatrud J. Prospective study of the association between sleep-disorded breathing and hypertension. $\mathrm{N}$ Engl $\mathrm{J}$ Med 2000;342:1378-1384.

14. Peker Y, Carlson J, Hedner J. Increased incidence of coronary artery disease in sleep apnoea: a long term follow-upp. Eur Respir J 2006;28:596-602.

15. Punjabi NM, Polotsky VY. Disorders of glucosae metabolism in sleep apnea. J Appl Physiol 2005;99:1998-2007.

16. Marin JM, Carrizo SJ, Vicente E, Agusti AG. Longterm cardiovascular outcomes in men with obstructive sleep apnoea-hypopnoea with or without treatment with continuous positive airway pressure: an observational study. Lancet 2005;365:1046-1053.

17. Peppard PE, Young T, Barnet JH, Palta M, Hagen EW, Hla KM. Increased prevalence of sleep-disordered breathing in adults. Am J Epidemiol 2013;177(9):10061014.

18. Nagappa M, Liao P, Wong J, Auckley D, Ramachandran SK, Memtsoudis S et al. Validation of the STOP-Bang Questionnaire as a screening tool for obstructive sleep apnea among different populations: A systematic review and meta-analysis. PloS ONE 2015;10(12):e0143697. doi:10.1371/journal.pone.0143697.

19. Pedrosa RP, Drager LF, Gonzaga CC, Sousa MG, de paula LKG, Amaro ACS et al. Obstructive sleep apnea: The most common secondary cause of hypertension associated with resistant hypertension. Hypertension 2011;58:811-817.

20. Chobanian AV, Bakris GL, Black HR, Cushman WC, Green LA, Izzo JL et al. for the Joint National Committee on Prevention, Detection, Evaluation and Treatment of High Blood Pressure, National Heart, Lung and Blood Institute; national High Blood Pressure Education Program Coordinating Committee. Seventh report of the Joint National Committee on Prevention, Detection, Evaluation and Treatment of High Blood Pressure. Hypertension 2003;42:12061252.

21. Sjostrom C, Lindberg E, Elmasry A, Hagg A, Svardsudd K, Janson C. Prevalence of sleep apnea and snoring in hypertensive men: a population based study. Thorax 2002;57:602-607.

22. Drager LF, Genta PR, Pedrosa RP, Nerbass FB, Gonzaga CC, Krieger EM, Lorenzi-Filho G. Characteristics and predictors of obstructive sleep apnea in patientes with systemic hypertension. Am J Cardiol 2010; 105:1135-1139.

23. Goncalves SC, Martinez D, Gus M, de Abreu-Silva EO, Bertoluci C, Dutra I et al. Obstructive sleep apnea 
and resistant hypertension: a case-control study. Chest 2007;132:1858-1862.

24. Logan AG, Perlikowski SM, Mente A, Tisler A, Tkacova R, Niroumand $M$ et al. High prevalence of unrecognized sleep apnea in drug-resistant hypertension. J Hypertens 2001;19:2271-2277.

25. Mooe T, Rabben T, Wiklund U, Franklin KA, Eriksson P. Sleep-disordered breathing in men with coronary artery disease. Chest 1996; 109:659-63.

26. Sorajja D, Gami AS, Somers VK, Berenbeck TR, Garcia-Touchard A, Lopez-Jimwnwz F. Independent association between obstructive sleep apnea and subclinical coronary artery disease. Chest 2008;133:927-33.

27. McNicholas WT, Bonsignore MR. Sleep apnoea as an independent risk factor for cardiovascular disease: current evidence, basic mechanisms and research priorities. Eur Respir J 2007;29:156-78.

28. Schafer H, Koehler U, Ewig S, Hasper E, Tasci S, Luderitz B. Obstructive sleep apnoea as a risk marker in coronary artery disease. Cardiology 1999;92:79-84.

29. Gottlieb DJ, Yenokyan G, Newman AB, O'Connor GT, Punjabi NM, Quan SF et al. Prospective study of obstructive sleep apnoea and incident coronary heart disease and heart failure:The Sleep Heart Health Study. Circulation 2010;122:352-60.
30. Newman AB, Nieto FJ, Guidey U, Lind BK, Redline S, Pickering TG et al. Relation of sleep-disordered breathing to cardiovascular disease risk factors: The Sleep Heart Health Study. Am J Epidemiol 2001,154:50-9.

31. Chaouat A, Weitzenblum E, Krieger J, Ifoundza T, Oswald M, Kessler R. Association of chronic obstructive pulmonary disease and sleep apnea syndrome. Am J Respir Crit Care Med 1995;151(1):8286.

32. Lopez-Acevedo MN, Torres-palacios A, Elena OcasioTascon M, Campos-Santiago z, Rodriguez-Cintron W. Overlap syndrome: an indication for sleep studies?: a pilot study. Sleep Breath 2009;13(4):409-413.

33. Strohl KP, Redline S. Recognition of obstructive sleep apnea. Am J Respir Crit Care Med 1996;154:279-289.

34. Fletcher EC, DeBehnke RD, Lovoi MS, Gorin AB. Undiagnosed sleep apnea in patients with essential hypertension. Annals of Internal Medicine. 1985;103(2):190-195. doi: 10.7326/0003-4819-103-2190.

35. Sanner B, Sturm A, Konermann M Coronary heart disease in patients with obstructive sleep apnea. Dtsch Med Wochenschr. 1996 Jul 26;121(30):931-5.

Summary: Obstructive sleep apnea is a very common disease, that is often undiagnosed in about $85 \%$ of patients. It is characterized by repeated breathing pauses during sleep that are caused by the complete or partial collapse of the upper respiratory airways, causing a decrease in oxygen saturation in the blood and consequently unrefreshing sleep.

In our study, we examined the clinical characteristics of 33 patients who performed a polysomnographic examination at the Special Hospital for Cardiovascular Rehabilitation "Hercegovina" at ZTC Banja Vrucica in the period from 01.01.2017. until 31.12.2017.

The aim of our research is to determine the frequency of risk factors for obstructive sleep apnea among our patients and to determine the presence of comorbidities.

In our group there was a mild male dominance (57.5\%), with an average age of 61 (SD 13.03). The largest number of patients (70\%) was in the age group 60 and over. BMI greater than 30 had $70 \%$ of patient. We found the neck circumference greater than $40 \mathrm{~cm}$ in $70 \%$ of the patients. $88.8 \%$ of patients had a high risk of sleep apnea (STOP BANG 5-8 points). One or more comorbidities had 75\% of the patients, most frequently among comorbidities were hypertension, coronary artery disease, COPD, diabetes and various arrhythmias.

Key words: sleep apnea, risk factors, comorbidities

\author{
Sanja Glišić \\ Cetinjska bb \\ 74270 Teslić \\ Mobtel: 065598171 \\ E mail: sanjaglisic2009@live.com
}

